\title{
Fostering complex learning-task performance through scripting student use of computer supported representational tools
}

Citation for published version (APA):

Slof, B., Erkens, G., Kirschner, P. A., Janssen, J., \& Phielix, C. (2010). Fostering complex learning-task performance through scripting student use of computer supported representational tools. Computers \& Education, 55(4), 1707-1720. https://doi.org/10.1016/j.compedu.2010.07.016

DOI:

10.1016/j.compedu.2010.07.016

Document status and date:

Published: 01/12/2010

Document Version:

Peer reviewed version

\section{Document license:}

CC BY-SA

Please check the document version of this publication:

- A submitted manuscript is the version of the article upon submission and before peer-review. There can be important differences between the submitted version and the official published version of record. People interested in the research are advised to contact the author for the final version of the publication, or visit the DOI to the publisher's website.

- The final author version and the galley proof are versions of the publication after peer review.

- The final published version features the final layout of the paper including the volume, issue and page numbers.

Link to publication

\section{General rights}

Copyright and moral rights for the publications made accessible in the public portal are retained by the authors and/or other copyright owners and it is a condition of accessing publications that users recognise and abide by the legal requirements associated with these rights.

- Users may download and print one copy of any publication from the public portal for the purpose of private study or research.

- You may not further distribute the material or use it for any profit-making activity or commercial gain

- You may freely distribute the URL identifying the publication in the public portal.

If the publication is distributed under the terms of Article $25 \mathrm{fa}$ of the Dutch Copyright Act, indicated by the "Taverne" license above, please follow below link for the End User Agreement:

https://www.ou.nl/taverne-agreement

Take down policy

If you believe that this document breaches copyright please contact us at:

pure-support@ou.nl

providing details and we will investigate your claim.

Downloaded from https://research.ou.nl/ on date: 26 Apr. 2023 
Fostering Complex Learning-task Performance through Scripting Student Use of Computer Supported Representational Tools

B. Slof ${ }^{1}$, G. Erkens ${ }^{1}$, P. A. Kirschner ${ }^{2}$, J. Janssen ${ }^{1}, \&$ C. Phielix ${ }^{1}$

1Utrecht University, P.O. Box 80.140, 3508 TC Utrecht, the Netherlands

b.slof@uu.nl; g.erkens@uu.nl; j.j.h.m.janssen@uu.nl; c.phielix@uu.nl

2Open Universiteit Nederland, P.O. Box 2960, 6401 DL Heerlen, the Netherlands

paul.kirschner@ou.nl 


\begin{abstract}
This study investigated whether scripting student use of computer supported representational tools fostered students' collaborative performance of a complex business-economics problem. Scripting the problem-solving process sequenced and made its phase-related part-task demands explicit, namely (1) determining core concepts, (2) proposing multiple solutions, and (3) coming to a final solution. The representational tools facilitated students in constructing specific representations of the domain (i.e., conceptual, causal, or mathematical) and were each suited for carrying out the part-task demands of a specific phase. Student groups in four experimental conditions had to carry out all part-tasks in a predefined order, but differed in the representational tool(s) they received during their collaborative problem-solving process. In three mismatch conditions, student groups received either a conceptual, causal, or simulation representational tool which supported them in only carrying out one of the three part-tasks. In the match condition, student groups received the three representational tools in the specified order, each matching the part-task demands of a specific problem phase. The results revealed that student groups in the match condition constructed more task-appropriate representations and had more elaborated and meaningful discussions about the domain. As a consequence, those student groups performed better on the complex learning-task. However, similar results were obtained by student groups who only received a representational tool for constructing causal representations for all part-tasks.
\end{abstract}

Keywords: Complex Learning-tasks, Computer Supported Collaborative Learningenvironments, External Representations, Pedagogical Issues, Secondary Education 


\section{Introduction}

There has been a recent surge in the interest of educational researchers for studying the effects of computer supported tools for fostering students' complex learning-task performance (Demetriadis, Papadopoulos, Stamelos, \& Fischer, 2008; Slof, Erkens, Kirschner, Jaspers, \& Janssen, 2010; Zydney, 2010). Carrying out complex learning-tasks requires students to actively engage in a dynamic process of sense-making (Kirschner, Buckingham Shum, \& Carr, 2003) by articulating and discussing multiple representations on the problem and their problem-solving strategy. Through externalizing one's knowledge, discussing this with peers, and establishing and refining the group's shared understanding of the domain, students often acquire new knowledge and skills and process them more deeply (Ding, 2009; Hmelo-Silver, Duncan, \& Chinn, 2007; Kirschner, Beers, Boshuizen, \& Gijselaers, 2008). Educators and instructional designers, however, should realize that students (e.g., novices) need ample instructional support to make their problem-solving process more efficient and effective (Kirschner, Sweller, \& Clark, 2006). Students tend to focus on superficial details of problems instead of focusing on the underlying principles of the domain (Corbalan, Kester, \& Van Merriënboer, 2009), and to employ weak problem-solving strategies such as working via a means-ends strategy towards a solution (Simon, Langley, \& Bradshaw, 1981; Van Merriënboer \& Kirschner, 2007). To this end, it would be beneficial to support students in acquiring different problem representations of the domain in which they are working and in using those representations to solve the given problem (Frederiksen \& White, 2002; Jonassen, 2003; Ploetzner, Fehse, Kneser, \& Spada, 1999).

Research on Computer Supported Collaborative Learning (CSCL) has shown that collaboratively constructing and discussing domain-specific representations beneficially affects complex learning-task performance (Fischer, Bruhn, Gräsel, \& Mandl, 2002; Lazakidou \& Retalis, 2010; Wegerif, McClaren, Chamrada, Schreuer, Mansour, Mikšátko et al., 2010). Embedding representational tools in a CSCL-environment can facilitate students' construction of different representations of the domain and, thereby, guide their interaction and, thus, their collaborative problem-solving process. A tool's ontology (i.e., objects, relations, rules for combining objects and relations) provides a specific kind of representational guidance which makes certain concepts and/or relationships (e.g., causal, mathematical) salient in favor of others. In this way, a tool's representational guidance supports externalization of knowledge and ideas about specific aspects of a domain (Ertl, Kopp, \& Mandl, 2008; Suthers, 2006; Van Bruggen, Boshuizen, \& Kirschner, 2003). This may foster students' understanding because it stimulates cognitive processes such as selecting 
relevant information, organizing information into coherent structures, and relating it to prior understanding (Liu, Chen, \& Chang, 2010; Shaw, 2010; Stull \& Mayer, 2007). Collaborative learning, due to its emphasis on dialogue and discussion, can stimulate the elaboration of these representations so that multiple perspectives on the domain and of the problem-solving strategy can arise (De Simone, Schmid, \& McEwan, 2001; Hmelo-Silver et al., 2007). When students are able to create a shared understanding of these different viewpoints and negotiate about them, this fosters their performance of complex learning-tasks (Ding, 2009; Erkens, Jaspers, Prangsma, \& Kanselaar, 2005; Mercer, Littleton, \& Wegerif, 2004). Although the educational benefits of representational tools are widely recognized, some studies report mixed or even negative findings and, thus, question how student interaction can best be guided (Bera \& Liu, 2006; Elen, \& Clarebout, 2007; Van Drie, Van Boxtel, Jaspers, \& Kanselaar, 2005). This inconsistency in the literature hinders educators and instructional designers in designing representational tools that foster students' performance of complex learning-tasks.

\subsection{Designing representational tools to foster complex learning-task performance}

\subsubsection{Drawbacks}

Since representational tools guide students in constructing and, thus, discussing specific representations of the domain, educators and instructional designers should realize that such tools are only appropriate for carrying out specific task demands (Ainsworth, 2006; Bodemer \& Faust, 2006; Schnotz \& Kürschner, 2008). The mere presence or availability of a representational tool does not, therefore, automatically support students in solving complex problems. Important here is that those problems are usually composed of fundamentally different phase-related part-tasks demands (e.g., Van Bruggen et al., 2003), namely:

- Problem orientation; determining core concepts and relating them to the problem,

- Problem solution; proposing solutions to the problem,

- Solution evaluation; determining suitability of the solutions and coming to a final solution to the problem.

Each problem phase requires a different representation on the domain and, thus, requires a representational tool with a specific kind of representational guidance. When the design of the tool is incongruent with the demands of one or more phase-related part-tasks this should negatively affect the student's performance of a complex learning-task (Slof et al., 2010; Suthers, 2006; Van Bruggen et al., 2003). Here, students cannot properly make sense of the domain and are, thus, hindered in acquiring and applying their understanding of the domain. 
To evoke elaborate and meaningful discussions about the domain requires a representational tool that (1) is in line with its users' capabilities and intentions, and (2) makes clear what its users can and should do with it (Kirschner, Martens, \& Strijbos, 2004; Veldhuis-Diermanse, 2002). If this is not the case, then students might experience at least two difficulties when using them. First, part-task related difficulties may arise when students do not have a realistic idea of the concepts and relationships they must use and how they should relate them to the problem. Due to this, students experience difficulties in constructing and interpreting their representations and, thus, in acquiring a well-developed understanding of the domain (Bodemer \& Faust, 2006; Brna, Cox, \& Good, 2001; Liu et al., 2010). Furthermore, students might see constructing the representation as an additional task-demand instead of as support. When this is the case, after the concepts are interrelated in the representation, students pay no further attention to the representation and, therefore, do not apply it to complete their learning-task (De Simone et al., 2001; Suthers, Hundhausen, \& Girardeau, 2003). Second, students in CSCL-environments often make use of multiple tools (e.g., chat tools, representational tools) in a non-sequential way which makes keeping track of each others' knowledge, ideas, and actions rather complicated. When students are unable to properly interpret the conveyed messages and relate them to each other, they experience communicative difficulties (Andriessen, Baker, Suthers, 2003; Barron, 2003; Erkens et al., 2005). Such difficulties often hinder students in elaborating on and meaningfully discussing the content of the domain. Whether students are able to have such discussions depends on how easily they can refer to and relate their contributions with those of others (i.e., deictic referencing, see Reinhard, Hesse, Hron, \& Picard, 1997; Suthers et al., 2003; Van Boxtel \& Veerman, 2001). Important here is that the provided computer tools support students in coordinating their collaboration process by carrying out communicative activities. That is, students have to make their own knowledge and ideas explicit to other group members. When made explicit, students must try to maintain a shared topic of discourse (i.e., achieve a common focus) and repair that focus if they notice focus divergence. Understanding and relating the relevance of individual messages may be hard when students are simultaneously discussing different topics. Student should, therefore, coordinate their topic of discourse by focusing (Erkens \& Janssen, 2008; Van Drie et al., 2005). Since not all concepts, principles, and procedures are relevant for carrying out a specific part-task students also must maintain the coherence and consistency of their shared understanding by checking (Van der Linden, Erkens, Schmidt, \& Renshaw, 2000). Furthermore, students must come to an agreement about relevant concepts, principles and procedures. Through argumentation they can try to change 
their partners' viewpoint to arrive at the best way to carry out a part-task or at a definition of concepts acceptable for all. In this argumentation process they try to convince the other/others by elaborating on their own point of view, and by explaining, justifying and accounting

(Andriessen et al., 2003; Kirschner et al, 2008).

\subsubsection{Scripting}

Just providing a user/student a tool does not guarantee use or proper use of that tool. To this end, students must understand what they can and should do with the tool and how its use is integrated within learning-task at hand (Kirschner et al., 2004; Veldhuis-Diermanse, 2002). Scripting has been advanced as a technique to ensure proper alignment between the design of the representational tool, student tool use, and the required task demands (Dillenbourg, 2002; Weinberger, Ertl, Fischer, \& Mandl, 2005). According to Dillenbourg a script is "a set of instructions regarding to how the group members should interact, how they should collaborate and how they should solve the problem" (p. 64). In our study students worked collaboratively on a case-based business-economics problem in which they had to advise an entrepreneur about changing the business strategy to increase profits (i.e., company result). Scripting was employed here to tailor the congruency of the representational guidance to the phase-related part-task demands of this complex learning-task. Integrating scripting with the availability of representational tools sequences and makes the different part-task demands explicit which should guide students in carrying out appropriate part-task related activities. That is, students may be evoked to carry out cognitive activities such as (1) discussing the goal of the problemsolving task/part-tasks, (2) discussing and selecting concepts, principles, and procedures in the domain, and (3) formulating and revising their decisions (Janssen, 2008; Jonassen, 2003). Students may also be induced to employ a proper problem-solving strategy and reflect on its suitability through carrying out meta-cognitive activities (Lazonder \& Rouet, 2008; Narciss, Proske, \& Koerndle, 2007). This requires that students discuss (1) how they should approach the problem (i.e., plan), (2) whether they have finished the part-tasks on time (i.e., monitor), and (3) how suitable their approach was (i.e., evaluate/reflect). Carrying out such cognitive and meta-cognitive activities should enable students to properly discuss both the content of the domain and their problem-solving strategy, fostering their performance of the complex learning-task (Hmelo-Silver et al., 2007; Ploetzner et al., 1999).

\subsubsection{Matching the tools' representational guidance to the phase-related part-tasks}

To gain insight into the phase-related part-tasks and their required domain-specific representations, a learning-task analysis (Anderson \& Krathwohl, 2001; Gagné, Briggs, \& Wagner, 1992) was conducted. Based on these insights, the sequence and the demands of the 
part-tasks were specified and part-task congruent representational tools were developed (see Table 1).

\section{**** PLEASE INSERT TABLE 1 ABOUT HERE ****}

In the problem orientation phase students have to explain what they think the problem is and describe what the most important factors are for solving it. Student interaction should, therefore, be guided towards selecting the core concepts needed to carry out this part-task and discussing how those concepts are qualitatively related to each other. The design of the representational tool should facilitate students in constructing and discussing a global qualitative problem representation by guiding and supporting them in conceptually relating the relevant concepts. Figure 1 shows an expert model of the concepts and their conceptual interrelationships involved in this study. The conceptual representational tool facilitates representation of the concepts and their interrelationships shown in Figure 1. Selecting and relating concepts that the students may regard as beneficial for solving the problem supports them in becoming more familiar with those concepts and in broadening their problem space. Students receiving the conceptual tool could, for example, make explicit that the 'company result' is related to the 'total profit' and 'efficiency result'. This should guide those students in elaborating (i.e., causal, mathematical) on the relationships in the two following problem phases, making it easier for them to find multiple solutions to the problem and to evaluate their effects.

\section{**** PLEASE INSERT FIGURE 1 ABOUT HERE ****}

In the problem solution phase students have to formulate several solutions to the problem and make clear how these interventions affect the outcomes (i.e., a company's results). Student interaction should, thus, be guided towards formulating multiple solutions and discussing how each of these solutions affects the selected core concepts by further specifying the relationships between the concepts and the proposed interventions. The representational tool should facilitate construction and discussion of a causal problem representation by causally relating concepts to each other and to possible interventions. Figure 2 shows an expert model of the concepts, the possible interventions and their causal interrelationships involved in this study. The causal representational tool facilitates representation of the concepts, interventions and their interrelationships shown in Figure 2. Selecting relevant concepts and interventions and causally relating them supports the effective exploration of the solution space and, thus, of finding multiple solutions to the problem. Students receiving the causal representational tool could, for example, make explicit that an intervention such as a employing a promotioncampaign (e.g., placing an advertisement in a paper) affects 'actual sales', which in turn 
affects 'total profit'. Only conceptually representing the interrelationships of the concepts, as in the first problem phase, is not expressive enough for this part-task since the relationships need to be further specified and students need additional information about the possible solutions. If this is not the case, then students are forced to come up with a solution (i.e., the advice) themselves without sufficient understanding of the underlying qualitative principles governing the domain.

\section{**** PLEASE INSERT FIGURE 2 ABOUT HERE ****}

Finally, in the solution evaluation phase students have to determine the financial consequences of their proposed interventions and formulate a final advice for the entrepreneur by discussing the suitability of the different interventions with each other. Student interaction should, therefore, be guided towards determining and comparing the financial consequences by discussing the mathematical relationships between the selected concepts. The representational tool must, thus, facilitate constructing and discussing a quantitative representation by specifying the relationships as equations. Figure 3 shows an expert model of the concepts and their mathematical interrelationships involved in this study. The simulation representational tool facilitates representation of the concepts and their interrelationships shown in Figure 3. Selecting relevant concepts and specifying the interrelationships as equations supports students in evaluating the effects of their proposed interventions and, thus, in coming to a suitable advice. Students receiving the simulation representational tool could, for example, simulate how an intervention such as employing a promotion-campaign affects the 'actual sales' and whether this affects the 'total profit. By entering values and adjusting them (i.e., increasing or decreasing), the values of the other related concepts are automatically computed. Since such quantitative representations can only be properly understood and applied when students have well-developed qualitative understanding of the domain, this kind of support is only appropriate for carrying out this type of part-task.

\subsection{Purpose, design and hypotheses}

The research reported on here was aimed at determining whether and how scripting the use of representational tools affects the performance of complex learning-tasks in CSCL. To study the effects of the representational scripting, four experimental conditions were defined by either matching or mismatching the tools' representational guidance to the part-task demands (see Table 2). 
Scripting the problem-solving process sequenced and made its phase-related part-task demands explicit, these part-task are (1) determining core concepts, (2) proposing multiple solutions, and (3) coming to a final solution (see Section 1.1.3). Student groups in four experimental conditions had to carry out all part-tasks in a predefined order, but differed in the representational tool(s) they received during their collaborative problem-solving process. In three mismatch conditions, students only received one of the representational tools (i.e., conceptual, causal, or simulation tool) for constructing the part-task related representations and carrying out all three part-tasks. The tools' representational guidance matched only one of the part-tasks and there was a mismatch for the other two. Those student groups were, thus, only supported in carrying out one of the part-tasks. In the fourth, match, condition, student groups received all three representational tools in a phased order, receiving the tool considered to be most suited to the part-task demands of each problem phase. Due to this presumed match between tools' representational guidance and the part-tasks, it was hypothesized that student groups in the match condition would:

(H1) construct representations that are more suited for carrying out the part-tasks;

(H2) have more elaborate and meaningful discussions, evidenced by carrying out more:

a) part-task related activities such as cognitive and meta-cognitive activities,

b) communicative activities to coordinate their part-related activities; and

(H3) arrive at better problem solutions.

\section{Method}

\subsection{Participants}

Participants were students from six business-economics classes in three secondary education schools in the Netherlands. The total sample consisted of 93 students (60 male, 33 female). The mean age of the students was 16.74 years $(S D=.77, \operatorname{Min}=15, \operatorname{Max}=18)$. The students were, within classes, randomly assigned to a total of 31 triads; seven triads in the match condition and eight triads in each of the three mismatch conditions. The administration and analysis of a pre-test to determine students' prior understanding of the domain did not reveal any significant differences between conditions and classes.

\subsection{CSCL-environment}

Students worked in a CSCL-environment called Virtual Collaborative Research Institute (VCRI, see Figure 4), a groupware application for supporting the collaborative performance of problem-solving tasks and research projects (see Erkens et al., 2005). For this study, the tools that are part of the VCRI were augmented with representational scripting. In the 
Assignment menu, students can find the description of the problem-solving task/part-tasks. Besides this, additional information sources such as a definition list, formula list, and clues for solving the problem were also available here. The Model menu enabled students in constructing and adjusting their representations by either adding or deleting relationships. At the start of the first lesson all diagram boxes - representing the different concepts - were placed on the left side of the Representational tool so students could select them when they wanted to add a new relationship. The Chat tool enabled synchronous communication and supported students in externalizing and discussing their knowledge and ideas. The chat history is automatically stored and can be re-read by the students. The Notes tool is an individual notepad that allowed students to store information and structure their own knowledge and ideas before making them explicit. The Co-writer is a shared text-processor where students could collaboratively formulate and revise their decisions. The Status bar is an awareness tool that displayed which group members were logged into the system and which tool a group member used at a specific moment.

The different conditions were information equivalent and only differed in the way that the representational tools were intended to guide student interaction and their complex learningtask performance.

\section{**** PLEASE INSERT FIGURE 4 ABOUT HERE}

\subsection{Scripting student tool use}

All student groups were coerced to carry out the part-tasks in a predefined order (i.e., used the same script) and could, thus, only start with a new part-task after finishing an earlier part-task. When group members agreed that a part-task was completed, they had to 'close' that phase in the assignment menu. This 'opened' a new phase, which had two consequences for all students, namely they were instructed to (1) carry out a new part-task and (2) revise their representation of the domain so it concurred with the answers they gave to the new part-task. Students in the mismatch conditions were facilitated in elaborating on their previously constructed representation. Since those students kept the same representational tool, all concepts and their relationships remained visible and could be revised as students seemed appropriate for carrying out their new part-task. Students in the match condition were facilitated in acquiring and applying a different qualitative or quantitative perspective of the domain. That is, the previously selected concepts remained visible and students were instructed to replace the relationships by specifying them in a causal manner or as equations with the aid of their new representational tool. 


\subsection{Procedure}

All student groups spent six, 45-minute lessons solving the problem during which each student worked on a separate computer. Before the first lesson, students received an instruction about the CSCL-environment, the complex learning-task, and the group composition. The instruction made it clear that their score on the complex learning-task would serve as a grade affecting their GPA. Students worked on the problem in the computer classroom where all actions and decisions were logged. During the lessons, the teacher was on stand-by for task related questions and a researcher was present for technical support.

\subsection{Measurement}

To gain insight in whether and how scripting student tool use affects their complex learningtask performance in CSCL, data concerning students' learning process (i.e., quality of the constructed representations and student interaction) as well as their learning results (i.e., complex learning-task performance) were collected.

\subsubsection{Quality of the constructed representations}

To examine the effect of condition on the quality of the constructed representations, a content analysis was conducted on all three phase-related representations. The representations were selected at the end of each problem phase, just before students 'closed' their part-task (see Section 2.3), and transferred from the log-files using the Multiple Episode Protocol Analysis (MEPA) program (Erkens, 2005). Then they were coded with respect to how many concepts and relationships were represented and whether they were represented correctly. It should be noted that the (nine) possible interventions were also coded as concepts since students receiving the causal tool were facilitated in representing them. When a concept was related to multiple other concepts, it received a code for each relationship and could, thus, be coded several times. The coding was done automatically with a MEPA-filter which makes use of 364 'if-then' decision rules containing explicit references to the concepts, the relationships and its correctness (based on the expert models, see Figures 1-3).

\subsubsection{Student interaction}

The chat-protocols were selected and transferred from the log-files using the MEPA program. The content of these chat-protocols is assumed to represent what students know and consider important for carrying out their problem-solving task (Chi, 1997; Moos \& Azevedo, 2008). Using so called 'concordancers' software (e.g., MEPA, Erkens; !Kwictex, Mercer et al., 2004) minimizes the work associated with coding the chat-protocols and maximizes coding allowing the content of chat-protocols to be searched for the occurrence of important words or phrases within their linguistic context to show their specific function in the dialogue. 
To examine the effect of condition on students' part-task related activities, two coding schemes were applied. Measurement of students' discourse topics provided insight into the cognitive, meta-cognitive and off-task activities carried out (see Table 3). The topics were hand-coded and Cohen's kappa was computed for three independently coded chat-protocols (3,532 lines) by two coders. An overall Cohen's Kappa of .70 was found, an intermediate to good result (Cicchetti, Lee, Fontana, \& Dowds, 1978). Measurement of students' interaction about the concepts, interventions and the ways of interrelating them provided insight into their discussion of the content of the domain (see Table 4). A problem here is that even within in a single sentence, multiple concepts or statements may be expressed and thus require multiple codes (Erkens \& Janssen, 2008; Strijbos, Martens, Prins, \& Jochems, 2006). With a MEPAfilter which makes use of 300 'if-then' decision rules, the utterances were automatically segmented into smaller, still meaningful, subunits. Punctuation marks (e.g., full stop, exclamation mark, question mark, comma) and connecting phrases (e.g., 'and if', or 'but if') were used to segment the utterances. After segmentation, the coding was done automatically with a MEPA-filter which makes use of 900 'if-then' decision rules containing explicit references to a concept, solution or relationship (e.g., name, synonyms, etc.) which were coded as representing that concept, solution or relationship. Overall Cohen's Kappa for concepts, solutions and relationships ranging from .68 to .83 , were reached compared to handcoding three chat-protocols $(3,020$ lines $)$.

\section{****PLEASE INSERT TABLE 3 ABOUT HERE**** ****PLEASE INSERT TABLE 4 ABOUT HERE****}

To examine the effect of the condition on students' communicative activities each utterance was coded with respect to the type of dialogue act used (see Table 5). A dialogue act is regarded as a communicative action which is elicited for a specific purpose representing a specific function in the dialogue (Erkens et al., 2005; Mercer et al., 2004). The coding was based on the occurrence of characteristic words or phrases (i.e., discourse markers; see Schiffrin, 1987) which indicate the communicative function of an utterance (see Table 5). This was done automatically with a MEPA-filter using 1,250 'if-then' decision rules that uses pattern matching to find typical words or phrases. When compared to hand-coding, an overall agreement of 79\% was reached and a Cohen's Kappa of .75 was found (Erkens \& Janssen, 2008). 


\subsubsection{Complex learning-task performance}

To examine the effect of the condition on complex learning-task performance, an assessment form for all three part-task and the quality of the final advice was developed. Table 6 provides a description of the aspects on which the decisions were evaluated, the number of items, and their internal consistency scores (i.e., Cronbach's alpha). The 41 items could all be coded as ' 0 ' (wrong), ' 1 ' (adequate) or '2' (good); the higher the code, the higher the quality of the decision. Groups could, thus, achieve a maximum score of 82 points for their learning-task performance ( 41 items $\times 2$ points) and a minimum of 0 points. The internal consistency score for the whole complex learning-task performance was .92 and for most subscales, internal consistency scores of .56 or above were obtained.

\section{****PLEASE INSERT TABLE 6 ABOUT HERE****}

\subsection{Analyses}

\subsubsection{Quality of the constructed representations}

Content analyses were conducted to examine the effect of condition on the quality of the constructed representations. To this end, students' part-task related representations of the concepts, their relationships and the correctness of those relationships were analyzed.

\subsubsection{Student interaction}

Multilevel analyses (MLAs) were used to examine the effects of condition on student interaction. This technique is suited to address the statistical problem of non-independence that is often associated with conducting studies on CSCL (Cress, 2008; Janssen, 2008; Strijbos \& Fischer, 2007). Many statistical techniques (e.g., $t$-test, ANOVA) assume scoreindependence and a violation of this assumption compromises the interpretation of the output of their analyses (e.g., $t$-value, standard error, $p$-value, see Kenny, Kashy, \& Cook, 2006). The non-independence was determined here by computing the intraclass correlation coefficient and its significance (Kenny et al.) for all dependent variables concerning student interaction. This coefficient demonstrated non-independence $(\alpha<.05)$ for all tests, justifying MLA for analyzing these data. MLA entails comparing the deviance of an empty model and a model with one or more predictor variable(s) to compute a possible decrease in deviance. The latter model is considered a better model when there is a significant decrease in deviance in comparison to the empty model (tested with a $\chi^{2}$-test). Almost all reported $\chi^{2}$-values were significant $(\alpha<.05)$ and, therefore, the estimated parameters of these predictor variables (i.e., effects of condition) were tested for significance. 


\subsubsection{Complex learning-task performance}

A one-way MANOVA was used to examine the effect of condition on complex learning-task performance. There was no need to use MLAs because the complex learning-task performance was measured at the group level instead of the student level. Since there were specific directions of the results expected (see Section 1.2) all analyses are one-sided.

\section{Results}

\subsection{Quality of the constructed representations}

The content analyses (see Figure 5) revealed several differences concerning the quality of the constructed representations between conditions. First, students in the match condition represented fewer concepts and relationships than students in both the conceptual and the causal conditions. Second, students in both the conceptual condition and the simulation conditions represented the relationships more correctly than students in the causal condition. Third, students in the simulation condition represented fewer concepts and relationships than students in the other conditions, though they were more successful in correctly relating the concepts to each other.

\section{****PLEASE INSERT FIGURE 5 ABOUT HERE****}

Furthermore, several conditions effects were obtained when analyzing the part-task related representations in relation to the phase-related part-tasks. First, compared to students in both the conceptual and the causal conditions, students in the match condition represented fewer concepts and relationships within their second and third representation than they did in their first. Second, compared to students in both the conceptual and the simulation conditions, students in the causal condition and students in the match condition varied more in whether they correctly represented the relationships.

As expected, students in the match condition differed in representing the content of domain when carrying out the different part-tasks. After constructing a mostly correct global representation, students became more selective in representing the concepts and specifying their relationships in a causal or mathematical manner.

\subsection{Student interaction}

\subsubsection{Cognitive, meta-cognitive and off-task activities}

MLAs revealed that condition was not a predictor for students' meta-cognitive activities $(\beta=1.74, p=.26)$, cognitive activities $(\beta=2.64, p=.20)$, and off-task activities $(\beta=-.30$, $p=.42$ ). The mean scores, standard deviations and condition effects (i.e., difference between match condition and non-matched conditions) for the different kinds of discourse topics are listed in Table 7. 
When analyzing the different discourse topics for the conditions separately, two condition effects were found. First, a significant category effect for meta-cognitive activities was found when comparing students in the match condition to students in the simulation condition $(\beta=4.57, p=.04)$. As indicated by the ${ }^{+}$and $^{-}$signs in Table 7 , students in the match condition exhibited more meta-cognitive activities compared to students in the simulation condition. Students in the simulation condition discussed whether they had finished their parttasks on time (i.e., monitoring) less compared to students in the match condition $(\beta=2.42$, $p=.03)$. Second, a significant category effect for cognitive activities was found when comparing students in the match condition with students in the simulation condition $(\beta=5.23$, $p=.04)$. Students in the simulation condition discussed fewer content-related discourse topics and formulated/revised their decisions (i.e., content) less often compared to students in the match condition $(\beta=3.82, p=.05)$. Finally, students in the simulation condition discussed what the goal of the problem-solving task and the different part-tasks was (i.e., preparation) less than students in the match condition $(\beta=0.72, p=.05)$.

Contrary to our expectations, students in the match condition only carried out more metacognitive and more cognitive activities than students in the simulation condition. No significant differences were obtained for the comparison with students in both the conceptual and the causal conditions.

\section{****PLEASE INSERT TABLE 7 ABOUT HERE****}

\subsubsection{Concepts, solutions and relations}

MLAs revealed that condition was not a significant predictor for the number and kinds of concepts $(\beta=2.41, p=.25)$, solutions $(\beta=1.27, p=.36)$ and relations $(\beta=1.73, p=.34)$ discussed. The mean scores, standard deviations and condition effects (i.e., difference between match condition and non-matched conditions) for the discussion of concepts, solutions and relations are shown in Table 8.

When analyzing these variables for the conditions separately, two condition effects were found. First, a marginally significant category effect for concepts was found when comparing students in the match condition to students in the simulation condition $(\beta=4.49, p=.07)$. Second, a significant category effect for relationships was found; students in the match condition discussed more and more different kinds of relationships than students in the simulation condition $(\beta=5.74, p=.05)$. It appeared that this was (marginally) the case for the conceptual $(\beta=1.54, p=.07)$ and the causal relationships $(\beta=3.85, p=.05)$.

Contrary to our expectations, students in the match condition only had more elaborated discussions of the domain than students in the simulation condition. No significant differences 
were obtained for the comparison with students in both the conceptual and the causal conditions.

\section{****PLEASE INSERT TABLE 8 ABOUT HERE****}

\subsubsection{Communicative activities}

MLAs revealed that condition was a (marginally) significant predictor for the communicative activities students exhibited when comparing students in the match condition to students in both the conceptual $(\beta=23.84, p=.06)$ and the simulation conditions $(\beta=42.00, p=.00)$. The mean scores, standard deviations and condition effects (i.e., difference between match condition and non-matched conditions) for the communicative activities are listed in Table 9. When analyzing students' communicative activities for the conditions separately, several category effects were found. First, a significant category effect for focusing was found; students in the match condition were better able to coordinate what their topic of discourse was than students in both the conceptual $(\beta=4.22, p=.05)$ and the simulation conditions ( $\beta=6.68, p=.02)$. Second, a significant category effect for checking was found; students in the match condition devoted more attention to guarding the coherence and consistency of their shared understanding of the domain than students in both the conceptual $(\beta=14.08$, $p=.04)$ and the simulation conditions $(\beta=23.03, p=.00)$. Finally, a significant category effect was found for argumentation; students in the match condition exhibited more argumentative activities than students in the simulation condition $(\beta=12.17, p=.02)$. As expected, students in the match condition were better able to establish and maintain shared understanding of the domain than students in both the conceptual and simulation conditions. These differences were, however, not found for the comparison with students in the causal condition.

\section{****PLEASE INSERT TABLE 9 ABOUT HERE****}

\subsection{Complex learning-task performance}

A One-way MANOVA on the total score for problem-solving showed a significant difference for condition $(F(3,27)=4.38, \mathrm{p}=.01)$. Bonferroni post hoc analyses revealed that student groups in the match condition scored significantly higher than student groups in both the conceptual $(p=.01 ; d=1.46)$ and the simulation conditions $(p=.01 ; d=1.48)$. When the results for the dependent variables were considered separately - using one-way ANOVAs with Bonferroni post hoc analyses - condition effects were found for 'justification' $(F(3,27)=4.85, p=.01)$ and 'correctness' $(F(3,27)=3.97, p=.01)$. The mean scores, standard deviations and condition effects (i.e., difference between match condition and nonmatched conditions) for the complex learning-task performance are listed in Table 10. The 
mean scores indicate that there were two significant differences between conditions. First, groups in the match condition scored significantly higher on 'justification' than groups in both the conceptual ( $p=.01 ; d=1.56)$ and simulation conditions ( $p=.01 ; d=1.56)$. Second, groups in the match condition scored significantly higher on 'correctness' than groups in both the conceptual $(p=.01 ; d=3.97)$ and simulation conditions $(p=.03 ; d=2.52)$.

As expected, student groups receiving part-task congruent representational tools scored higher on complex learning-task performance. Although expected, no significant differences were obtained between student groups in the match condition and the causal condition.

\section{****PLEASE INSERT TABLE 10 ABOUT HERE****}

\subsection{Anomalies}

Since our hypotheses were focused on comparing the performance of student groups in the match condition to student groups in the mismatch conditions our analyses and results, thus far, have been reported accordingly. However, the means and standard deviations (see Tables 7-10) indicated that student interaction and complex learning-task performance of student groups in the causal condition and the match condition were quite similar. Student groups in both the causal and match conditions, in contrast to those in the other conditions, were facilitated to construct causal representations of the domain. This could have supported those groups in causal reasoning about the domain, a learning activity that is regarded as beneficial for learning (Jonassen \& Ionas, 2008; McCrudden, Schraw, Lehman, \& Poliquin, 2007). Guiding students' causal reasoning about the content of the domain might, thus, account for the differences in learning process (i.e., student interaction) and learning results (i.e., complex learning-task performance). Since these are noteworthy results, additional, two-sided analyses were carried out to determine whether the results obtained for student groups in the match condition also applied for student groups in the causal condition.

MLAs revealed that students in the causal condition also exhibited more part-task related and communicative activities than students in the simulation condition. Students in the causal condition (marginally) (1) exhibited more meta-cognitive activities $(\beta=7.56, p=.04)$ and off-task activities $(\beta=2.09, p=.07)$ and (2) discussed more and different kinds of relationships $(\beta=7.78, p=.07)$. Also, students in the causal condition were significantly better able to coordinate their part-task related activities $(\beta=46.56, p=.05)$. These results were obtained for all categories. A One-way MANOVA with Bonferroni post hoc analyses revealed that student groups in the causal condition marginally significantly outperformed student groups in both the conceptual $(p=.08 ; d=1.14)$ and the simulation conditions $(p=.08 ; d=1.16)$ on the complex learning-task performance. 
These results indicate that the problem-solving process of student groups in the causal condition were also efficient and effective.

\section{Discussion}

Embedding representational tools in CSCL-environments is often regarded as beneficial for learning. Such tools can facilitate students' construction and discussion of different representations of the domain and, thereby, guiding their learning process and foster their learning-task performance (Fischer et al., 2002; Wegerif et al., 2010). Although its importance is widely recognized, there are, however, also studies that report mixed or negative effects on learning (Elen \& Clarebout, 2007; Van Drie et al., 2005). An important reason for these contrasting findings seems that the complexity of the learning-task is not properly taken into account when designing representational tools. Since a representational tool is often suited for coping with the demands of a specific task, it hinders students in carrying out learning-tasks which consist of multiple part-tasks (Ainsworth, 2006; Van Bruggen et al., 2003).

The present study, therefore, examined whether and how embedding part-task congruent representational tools in a CSCL-environment fostered student collaborative problem-solving performance. Scripting the problem-solving process sequenced and made its phase-related part-task demands explicit, namely (1) determining core concepts, (2) proposing multiple solutions, and (3) coming to a final solution. By doing so, each problem phase could be foreseen with a part-task congruent representational tool. Scripting student use of representational tools was aimed at guiding their learning process (i.e., quality of the constructed representation and student interaction) and their learning results (i.e., complex learning-task performance). The results indicate that student groups who received the complete array of tools (i.e., match condition) were indeed stimulated in their complex learning-task performance. That is, those groups formulated better decisions with respect to the part-tasks and came up with better final solutions to the problem than students in both the conceptual and the simulation conditions. This difference in learning results might be explained by the differences concerning students' learning process. Students in the match condition started by constructing a broad representation and gradually became more selective in representing the concepts and specifying their relationships in a causal or mathematical manner. This is the way that solving such a problem should theoretically be carried out (e.g., Van Merriënboer \& Kirschner, 2007). In contrast, students who only had access to one of the representational tools (i.e., conceptual, causal, or simulation) represented more or less the same concepts and relationships and were, thus, less occupied with fine-tuning their 
representations to the different part-task demands. Although the quality of the constructed representation differed for each part-task, almost no differences between the conditions concerning students' part-task related activities were obtained. Since student groups in all conditions had to construct a representation of the domain for each part-task, the learning activity in itself did no differ per condition. So perhaps students in all conditions were stimulated to discuss the content of the domain and their problem-solving strategy. This explanation seems consistent with the literature on CSCL which shows that the collaborative construction of external representations stimulates students' cognitive and meta-cognitive activities (e.g., De Simone et al., 2001). On the other hand, the lack of differences might also be due to the role of scripting. Structuring the problem-solving process into three phases, each focusing on one of the part-tasks, could have affected students' part-task related activities in the same manner (Dillenbourg, 2002; Kirschner et al., 2008). Whereas the discussion about the domain and the problem-solving strategy were very quite the same, students in the match condition exhibited more communicative activities than students in both the conceptual and simulation conditions. That is, they were better able to establish and maintain a shared understanding of the domain, which is regarded as a prerequisite for having a meaningful discussion of the domain (e.g., Van der Linden et al., 2000). It seems that the deictic power of the representational tool hindered students in establishing and maintaining shared understanding of the domain (Suthers et al., 2003; Van Boxtel \& Veerman, 2001). In other words, when students are unable to specify (i.e., conceptual tool) or being forced to explicitly specify (i.e., simulation tool) the relationship between concepts this hinders students in properly referring to and relating their contributions in CSCL-environments.

Although the results indicate that scripting student tool use seems beneficial for problemsolving and learning, there were some contrasting findings that require further discussion. First, student interaction and complex learning-task performance in the match condition was very similar to that in the causal condition. Since students in both conditions received the causal representational tool they were both facilitated in constructing and discussing a causal domain representation. Supporting students' causal reasoning seems, thus, important for learning (Jonassen \& Ionas, 2008; McCrudden et al., 2007). This result raises questions about whether constructing and applying multiple representations of a domain is beneficial for complex learning-task performance. When students regard a specific representation as beneficial for learning and/or encounter difficulties in combining multiple representations, they might choose to stick with a more familiar one and make no attempt to combine them (Ainsworth, 2006; Bodemer \& Faust, 2006). Second, students in the causal condition 
represented more concepts and relationships in comparison to students in the other conditions. This evoked more elaborate discussions of the domain which could have supported them in carrying out their complex learning-task. It is, however, noteworthy that the relationships that they represented were more often incorrect in comparison to the conceptual and the simulation conditions. The construction and discussion of representations might, thus, be more important for complex learning-task performance than the correctness of the representations (Brna et al, 2001; Cox, 1999). It might also be that permitting students to make errors during their complex learning-task performance may provide opportunities for learning. In this way, construction of incorrect representations can be regarded as a productive exercise in failure (Kapur, 2008).

\section{Implications and future research}

The obtained results mainly confirmed our expectations and are in line with those of others who stress the importance of sequencing and interrelating multiple (i.e., qualitative and quantitative) representations of the knowledge domain during the collaborative performance of a complex learning-task (Ertl et al., 2008; Jonassen, 2003; Ploetzner et al., 1999;

Frederiksen \& White, 2002). These results also have several implications for designing learning-environments (e.g., CSCL-environments) aimed at fostering students' complex learning-task performance. Combining the advantages of scripting and using multiple presentational tools facilitates students in constructing and discussing different representations of the domain. When properly matched to the part-task demands, the complementary function of those representations can evoke elaborated and meaningful discussion of the domain and foster students' complex learning-task performance (e.g., Ainsworth, 2006). To our knowledge, such an approach has not been used in other studies. Ertl et al., for example, used a condition in which scripting was employed to structure the problem-solving process and a specific representation was applied. Their design, however, did not allow them to compare the effects found with those of conditions in which scripting and student use of multiple representational tools were combined. However, when interpreting the results and the implications of this study one has to take into consideration that there were contrasting findings that require additional research to investigate:

- whether students indeed require qualitative as well as quantitative representations during their collaborative performance of complex learning-tasks,

- whether students combine qualitative and quantitative representations during their collaborative performance of complex learning-tasks, and 
- how constructing different representations affects the quality (i.e., correctness) of students' discussions of the domain.

\section{References}

Ainsworth, S. (2006). DeFT: A conceptual framework for considering learning with multiple representations. Learning and Instruction, 16, 183-198.

Anderson, L. W., \& Krathwohl, D. R. (2001). A taxonomy for learning, teaching, and assessing: A revision of Bloom's taxonomy of educational objectives. New York: Longman.

Andriessen, J., Baker, M., \& Suthers, D. D. (2003). Argumentation, computer support, and the educational context of confronting cognitions. In J. Andriessen, M. Baker, \& D. D. Suthers, (Eds.), Cognitions: Arguing to learn (pp. 1-25). Dordrecht, The Netherlands: Kluwer Academic Press.

Barron, B. (2003). When smart groups fail. Journal of the Learning Sciences, 12, 307-359.

Bera, S., \& Liu, M. (2006). Cognitive tools, individual differences, and group processing as mediating factors in a hypermedia environment. Computers in Human Behavior, 22, 295-319.

Bodemer, D., \& Faust, U. (2006). External and mental referencing of multiple representations. Computers in Human Behavior, 22, 27-42.

Brna, P., Cox, R., \& Good, J. (2001). Learning to think and communicate with diagrams: 14 questions to consider. Artificial Intelligence Review, 15, 115-134.

Chi, M. T. H. (1997). Quantifying qualitative analyses of verbal data: A practical guide. Journal of the Learning Sciences, 6, 271-315.

Cicchetti, D. V., Lee, C., Fontana, A. F., \& Dowds, B. N. (1978). A computer program for assessing specific category rater agreement for qualitative data. Educational and Psychological Measurement, 38, 805-813.

Corbalan, G., Kester, L., \& Van Merriënboer, J. J. G. (2009). Selecting learning tasks: Effects of adaptation and shared control on learning efficiency and task involvement. Contemporary Educational Psychology, 33, 733-756.

Cox, R. (1999). Representation construction, externalised cognition and individual differences. Learning and Instruction, 9, 343-363.

Cress, U. (2008). The need for considering multilevel analysis in CSCL research - An appeal for the use of more advanced statistical methods. International Journal of ComputerSupported Collaborative Learning, 3, 69-84. 
Demetriadis, S. N., Papadopoulos, P. M., Stamelos, I. G., Fischer, F. (2008). The effect of scaffolding students' context-generating cognitive activity in technology-enhanced case-based learning. Computers and Education, 51, 939-954.

De Simone, C., Schmid, R. F., \& McEwan, L. A. (2001). Supporting the learning process with collaborative concept mapping using computer-based communication tools and processes. Educational Research and Evaluation, 7, 263-283.

Dillenbourg, P. (2002). Over-scripting CSCL: The risks of blending collaborative learning with instructional design. In P. A. Kirschner (Ed.), Three worlds of CSCL: Can we support CSCL? (pp. 61-91). Heerlen, The Netherlands: Open Universiteit Nederland.

Ding, N. (2009). Content analysis: Visaualizing the sequential process of knowledge elaboration in computer-supported collaborative problem-solving. Computers and Education, 52, 509-519.

Elen, J., \& Clarebout, G. (2007). Supporting learning: Increasing complexity? Computers in Human Behavior, 23, 1162-1166.

Erkens, G. (2005). Multiple Episode Protocol Analysis (MEPA). Version 4.10. Utrecht University, The Netherlands.

Erkens, G., \& Janssen, J. (2008). Automatic coding of online collaboration protocols. International Journal of Computer-Supported Collaborative Learning, 3, 447-470.

Erkens, G., Jaspers, J., Prangsma, M., \& Kanselaar, G. (2005). Coordination processes in computer supported collaborative writing. Computers in Human Behavior, 21, $463-$ 486.

Ertl, B., Kopp, B., \& Mandl, H. (2008). Supporting learning using external representations. Computers and Education, 51, 1599-1608.

Fischer, F., Bruhn, J., Gräsel, C., \& Mandl, H. (2002). Fostering collaborative knowledge construction with visualization tools. Learning and Instruction, 12, 213-232.

Frederiksen, J. R., \& White, B. Y. (2002). Conceptualizing and constructing linked models: Creating coherence in complex knowledge systems. In P. Brna, M. Baker, K. Stenning, \& A. Tiberghein (Eds.). In the role of communication in learning to model. (pp. 69-96). Mahwah, New Jersey: Lawrence Erlbaum Associates.

Gagné, R. M., Briggs, L. J., \& Wagner, W. W. (1992). Principles of instructional design. (4 ${ }^{\text {th }}$ ed.). Forth Worth: Harcourt Brace Jovanovich.

Hmelo-Silver, C. E., Duncan, R. G., \& Chinn, C. A. (2007). Scaffolding and achievement in problem-based and inquiry learning: A response to Kirschner, Sweller, and Clark (2006). Educational Psychologist, 42, 99-107. 
Janssen, J. (2008). Using visualizations to support collaboration and coordination during computer-supported collaborative learning. Ph.D. thesis, Utrecht University, The Netherlands.

Jonassen, D. H. (2003). Using cognitive tools to represent problems. Journal of Research on Technology in Education, 35, 362-381.

Jonassen, D. H., \& Ionas, I. G. (2008). Designing effective support for causal reasoning. Educational Technology Research and Development, 56, 287-308.

Kapur, M. (2008). Productive Failure. Cognition and Instruction, 26(3), 379-424.

Kenny, D. A., Kashy, D. A., \& Cook, W. L. (2006). Dyadic data analysis. New York/London: The Guilford Press.

Kester, L., Kirschner, P. A., \& Corbalan, G. (2007). Designing support to facilitate learning in powerful electronic learning environments. Computers in Human Behavior, 23, 10471054.

Kirschner, P. A., Beers, P. J., Boshuizen, H. P. A., \& Gijselaers, W. H. (2008). Coercing shared knowledge in collaborative learning environments. Computers in Human Behavior, 24, 403-420.

Kirschner, P. A., Buckingham Shum, S. J., \& Carr, C. S. (2003). Visualizing argumentation: software tools for and educational sense-making. London: Springer-Verlag.

Kirschner, P. A., Martens, R. L., \& Strijbos, J. W. (2004). CSCL in higher education? A framework for designing multiple collaborative environments. In J. W. Strijbos, P. A. Kirschner, \& R. L. Martens (Eds.), What we know about CSCL, and implementing it in higher education (pp. 3-30). Boston: Kluwer Academic Publishers.

Kirschner, P. A., Sweller, J., \& Clark, R. E. (2006). Why minimal guidance during instruction does not work; An analysis of the failure of constructivist, discovery, problem-based, experiential, and inquiry-based teaching. Educational Psychologist, 4(2), 75-86.

Lazakidou, G., \& Retalis, S. (2010). Using computer supported collaborative learning strategies for helping students acquire self-regulated problem-solving skills in mathematics. Computers and Education, 54, 3-13.

Lazonder, A. W., \& Rouet, J. F. (2008). Information problem solving instruction: Some cognitive and metacognitive issues. Computers in Human Behavior, 24, 753-765.

Liu, P. L., Chen, C. J.., \& Chang, Y. J. (2010). Effects of a computer-assisted concept mapping learning strategy on EFL college students' English reading comprehension. Computers and Education, 54, 436-445. 
McCrudden, M. T., Schraw, G., Lehman, S., \& Poliquin, A. (2007). The effect of causal diagrams on text learning. Contemporary Educational Psychology, 32, 367-388.

Mercer, N., Littleton, K., \& Wegerif, R. (2004). Methods for studying the processes of interaction and collaborative activity in computer-based educational activities. Technology, Pedagogy and Education, 13, 195-212.

Moos, D. C., \& Azevedo, R. (2008). Monitoring, planning, and self-efficacy during learning with hypermedia: The impact of conceptual scaffolds. Computers in Human Behavior, 24, 1686-1706.

Narciss, S., Proske, A., \& Koerndle, H. (2007). Promoting self-regulated learning in webbased learning environments. Computers in Human Behavior, 23, 1126-1144.

Ploetzner, R., Fehse, E., Kneser, C., \& Spada, H. (1999). Learning to relate qualitative and quantitative problem representations in a model-based setting for collaborative problem solving. Journal of the Learning Sciences, 8, 177-214.

Reinhard, P., Hesse, F. W., Hron, A., \& Picard, E. (1997). Manipulable graphics for computer-supported problem solving. Journal of Computer Assisted Learning, 13, $148-162$.

Schiffrin, D. (1987). Discourse markers. Cambridge, MA: Cambridge University Press.

Schnotz, W., \& Kürschner, C. (2008). External and internal representations in the acquisition and use of knowledge: visualization effects on mental model construction. Instructional Science, 36, 175-190.

Shaw, R. S. (2010).A study of learning performance of e-learning materials design with knowledge maps. Computers and Education, 54, 253-264.

Simon, H. L., Langley, P. W., \& Bradshaw, G. (1981). Scientific discovery as problem solving. Syntheses, 47, 1-27.

Slof, B., Erkens, G., Kirschner, P. A., Jaspers, J. G. M., \& Janssen, J. (2010). Guiding students' online complex learning-task behavior through representational scripting. Computers in Human Behavior, 26, 927-939.

Strijbos, J.-W., \& Fischer, F. (2007). Methodological challenges for collaborative learning research. Learning and Instruction, 17, 389-393.

Strijbos, J.-W., Martens, R. L., Prins, F. J., \& Jochems, W. M. G. (2006). Content analysis: What are they talking about? Computers and Education, 46, 29-48.

Stull, A. T., \& Mayer, R. E. (2007). Learning by doing versus learning by viewing: Three experimental comparisons of learner-generated versus author-provided graphic organizers. Journal of Educational Psychology, 99, 808-820. 
Suthers, D. D. (2006). Technology affordances for intersubjective meaning making: A research agenda for CSCL. International Journal of Computer-Supported Collaborative Learning, 1, 315-337.

Suthers, D. D., Girardeau, L. E., \& Hundhausen, C. D. (2003). Comparing the roles of representations in face-to-face and online computer supported collaborative learning. Computers and Education, 41, 335-351.

Van Boxtel, C., \& Veerman, A. (2001). Diagram-mediated collaborative learning diagrams as tools to provoke and support elaboration and argumentation. Paper presented at the Euro CSCL, Maastricht.

Van Bruggen, J. M., Boshuizen, H. P. A., \& Kirschner, P. A. (2003). A cognitive framework for cooperative problem solving with argument visualization. In P. A. Kirschner, S. J. Buckingham-Shum, \& C. S. Carr (Eds.), Visualizing Argumentation: Software tools for collaborative and educational sense-making. (pp. 25-47). London: Springer.

Van der Linden, J. L., Erkens, G., Schmidt, H., \& Renshaw, P. (2000). Collaborative learning. In P. R. J. Simons, J. L. Van der Linden, \& T. Duffy (Eds.), New learning (pp. 1-19). Dordrecht: Kluwer Academic Publishers.

Van Drie, J., Van, Boxtel, C., Jaspers, J., \& Kanselaar, G. (2005). Effects of representational guidance on domain specific reasoning in CSCL. Computers in Human behavior, 21, $575-602$.

Van Merriënboer, J. J. G., \& Kirschner, P. A. (2007). Ten steps to complex learning. A systematic approach to four-component instructional design. New Jersey: Lawrence Erlbaum Associates.

Veldhuis-Diermanse, A. E. (2002). CSCLearning? Participation, learning activities and knowledge construction in computer-supported collaborative learning in higher education. Unpublished Ph.D. thesis, Wageningen University, The Netherlands.

Wegerif, R., McClaren, B. M., Chamrada, M., Schreuer, O., Mansour, N., Mikšátko, J., \& Williams, M. (2010). Exploring creative thinking in graphically synchronous dialogues. Computers and Education, 54, 613-621.

Weinberger, A., Ertl, B., Fischer, F., \& Mandl, H. (2005). Epistemic and social scripts in computer-supported collaborative learning. Instructional Science, 33, 1-30.

Zydney, J. M. (2010). The effect of multiple scaffolding tools on students' understanding, consideration of different representations, and misconceptions of a complex problem. Computers and Education, 54, 360-370. 



\section{Table 1}

Congruence between Representational Tool and Phase-related Part-task Demands

\begin{tabular}{|c|c|c|c|}
\hline Problem phase & Task demand & Representational tool & Representational guidance \\
\hline Problem orientation & $\begin{array}{l}\text { Determining core concepts and relating } \\
\text { them to the problem }\end{array}$ & Conceptual & $\begin{array}{l}\text { Representing concepts and their conceptual } \\
\text { relationships }\end{array}$ \\
\hline Problem solution & $\begin{array}{l}\text { Proposing multiple solutions to the } \\
\text { problem }\end{array}$ & Causal & $\begin{array}{l}\text { Representing causal relationships between } \\
\text { the concepts and the possible solutions }\end{array}$ \\
\hline Solution evaluation & $\begin{array}{l}\text { Determining suitability of the solutions } \\
\text { and coming to a final solution to the } \\
\text { problem }\end{array}$ & Simulation & $\begin{array}{l}\text { Representing mathematical relationships } \\
\text { between the concepts and enabling } \\
\text { manipulation of their values }\end{array}$ \\
\hline
\end{tabular}


Table 2

Overview of the Experimental Conditions

\begin{tabular}{|c|c|c|c|c|}
\hline \multirow[t]{2}{*}{ Condition } & \multicolumn{3}{|c|}{ Problem phases and provided representational tool } & \multirow[t]{2}{*}{ Match/mismatch } \\
\hline & Problem orientation & Problem solution & Solution evaluation & \\
\hline Conceptual & Conceptual tool & Conceptual tool & Conceptual tool & Match for the orientation phase only \\
\hline Causal & Causal tool & Causal tool & Causal tool & Match for the solution phase only \\
\hline Simulation & Simulation tool & Simulation tool & Simulation tool & Match for the evaluation phase only \\
\hline Match & Conceptual tool & Causal tool & Simulation tool & Match for all problem phases \\
\hline
\end{tabular}


Table 3

Coding and Category Kappa's ( $\left.K_{c}\right)$ of Students' Meta-cognitive, Cognitive and Off-task Activities

\begin{tabular}{lllc}
\hline Activities & Discourse topic & Discussion of & $K_{c}$ \\
\hline Meta-cognitive & & & .69 \\
& Planning & the problem-solving strategy; how and when the group has to carry out a specific activity & .58 \\
& Monitoring & whether they have finished the part-tasks on time & .56 \\
& Evaluating & the suitability of their problem-solving strategy & .64 \\
Cognitive & & & .65 \\
& Preparation & the goal of the problem-solving task and the different part-tasks & .45 \\
& Executing & content-related topics and formulating/revising their decisions to the part-tasks & .70 \\
& Ending & how, where, and when their decisions need to be registered & .51 \\
& & & .76 \\
& Social & non-task related topics & .80 \\
& Technical & problems with the CSCL-environment & .60 \\
\hline
\end{tabular}

Table 4

Coding and Category Kappa's $\left(K_{c}\right)$ MEPA-filter of Students' Discussion of the Domain

\begin{tabular}{llc}
\hline Categories & Discussion of the & $K_{c}$ \\
\hline Concepts & business-economics concepts & .83 \\
Solutions & possible interventions & .75 \\
Relations & different kinds of interrelationships & .68
\end{tabular}




\begin{tabular}{lll} 
Conceptual & definition/meaning of a concept/solution & .69 \\
Causal & causal relationship within/between concepts/solutions & .73 \\
Mathematical & quantitative relationships within/between concepts & .62 \\
\hline
\end{tabular}

Table 5 
Coding of Students' Communicative Activities

\begin{tabular}{|c|c|c|c|}
\hline Activities & Dialogue Act & Description & Example discourse marker \\
\hline \multirow[t]{5}{*}{ Focusing } & Elicitative proposal for action & Proposition for action & Let's start with the first part-task? \\
\hline & Elicitative question open & $\begin{array}{l}\text { Open question with a lot of } \\
\text { alternatives }\end{array}$ & $\begin{array}{l}\text { Shall we fist look at the description of the assignment or at the } \\
\text { description of the part-tasks? }\end{array}$ \\
\hline & Imperative action & Command to perform an action & Finish the decision to the second part-task \\
\hline & Imperative focus & Command for attention & Look at the representational tool! \\
\hline & Elicitative question verify & $\begin{array}{l}\text { Question that can only be } \\
\text { answered with yes or no }\end{array}$ & Do you refer to the company result?? \\
\hline \multirow[t]{4}{*}{ Checking } & Elicitative question set & $\begin{array}{l}\text { Question where the alternatives } \\
\text { are already given (set) }\end{array}$ & Are you for or against increasing sales? \\
\hline & Responsive confirm & Confirming answer & Yes, we indeed should start a promotion-campaign \\
\hline & Responsive deny & Denying answer & No, that is not a good solution \\
\hline & Responsive accept & Accepting answer & Oh, Yes that $\mathrm{OK}$ \\
\hline \multirow[t]{6}{*}{ Argumentation } & Argumentative reason & Reason & Because this solution does not affect our costs \\
\hline & Argumentative against & Objection & But this would cost more money \\
\hline & Argumentative conditional & Condition & If we increase the selling price... \\
\hline & Argumentative then & Consequence & Then the cost price decreases \\
\hline & Argumentative disjunctive & Disjunctive & $\begin{array}{l}\text { We can increase the actual sales through a promotion-campaign or } \\
\text { by decreasing the selling price or by .... }\end{array}$ \\
\hline & Argumentative conclusion & Conclusion & $\begin{array}{l}\text { Thus we can conclude that the third solution leads to the best } \\
\text { company result. }\end{array}$ \\
\hline
\end{tabular}

Table 6 
Items and Reliability of Complex Learning-task Performance

\begin{tabular}{|c|c|c|c|}
\hline Criteria & Description & Items & $\alpha$ \\
\hline Suitability & Whether the groups' decisions were suited to the different part-tasks & 9 & .81 \\
\hline Elaboration & $\begin{array}{l}\text { Number of different business-economics concepts or financial consequences incorporated in the decisions to the } \\
\text { different part-tasks }\end{array}$ & 9 & .56 \\
\hline Justification & Whether the groups justified their decisions to the different part-tasks & 9 & .71 \\
\hline Correctness & $\begin{array}{l}\text { Whether the groups used the business-economics concepts and their interrelationships correctly in their decisions to } \\
\text { the different part-tasks }\end{array}$ & 9 & .68 \\
\hline Continuity & Whether the groups made proper use of the decisions from a prior problem phase & 2 & .67 \\
\hline Quality advice & $\begin{array}{l}\text { Whether the groups gave a proper final advice } \\
\text { - Number of business-economics concepts incorporated in the advice } \\
\text { - Number of financial consequences incorporated in the advice } \\
\text { - Whether the final advice conformed to the guidelines provided }\end{array}$ & 3 & .76 \\
\hline Total score & Overall score on the complex learning-task performance & 41 & .92 \\
\hline
\end{tabular}

Table 7

Multilevel Analyses for Effects of Match Condition versus Non-matched Conditions concerning Students ' Metacognitive, Cognitive and Off-task Activities 


\begin{tabular}{|c|c|c|c|c|c|c|c|}
\hline & $\begin{array}{l}\text { Conceptual } \\
\text { condition } \\
\left(n_{\text {student }}=24\right)\end{array}$ & $\begin{array}{l}\text { Causal } \\
\text { condition } \\
\left(n_{\text {student }}=24\right)\end{array}$ & $\begin{array}{l}\text { Simulation } \\
\text { condition } \\
\left(n_{\text {student }}=24\right)\end{array}$ & $\begin{array}{l}\text { Match } \\
\text { condition } \\
\left(n_{\text {student }}=21\right)\end{array}$ & $\begin{array}{l}\text { Effects } 1 \\
\text { conditio } \\
\left(N_{\text {student }}=\right.\end{array}$ & & \\
\hline & $M(S D)$ & $M(S D)$ & $M(S D)$ & $M(S D)$ & $\chi^{2}(3)$ & $\beta$ & $S E$ \\
\hline Meta-cognitive ${ }^{*}$ & $23.54(9.12)$ & $30.32(18.80)$ & $17.65(12.38)-$ & $26.91(13.20)+$ & 17.15 & 1.74 & 2.66 \\
\hline Planning & $4.54(3.02)$ & $6.59(5.80)$ & $2.96(2.42)$ & $5.32(4.69)$ & 9.03 & 0.73 & 0.77 \\
\hline Monitoring ${ }^{*}$ & $13.33(5.79)$ & $16.95(11.17)$ & $10.43(6.81)-$ & $15.27(7.17)+$ & 13.05 & 1.00 & 1.40 \\
\hline Evaluating & $5.67(2.35)$ & $6.77(4.41)$ & $4.26(4.45)$ & $6.32(4.29)$ & 6.56 & 0.35 & 0.76 \\
\hline Cognitive $^{*}$ & $20.71(11.08)$ & $23.68(17.81)$ & $15.57(11.11)-$ & $25.73(11.94)+$ & 15.27 & 2.64 & 3.03 \\
\hline Preparation $^{*}$ & $2.83(2.60)$ & $4.23(3.49)$ & $1.83(2.10)-$ & $3.32(1.94)+$ & 7.39 & 0.25 & 0.46 \\
\hline Executing $^{*}$ & $14.54(8.56)$ & $15.68(11.79)$ & $11.26(8.56)-$ & $18.59(10.03)+$ & 12.88 & 2.09 & 2.24 \\
\hline Ending & $3.33(2.78)$ & $3.77(4.06)$ & $2.48(2.02)$ & $3.82(2.84)$ & 3.71 & 0.28 & 0.63 \\
\hline Off-task & $9.96(10.14)$ & $9.82(7.42)$ & $5.78(3.53)$ & $9.41(8.48)$ & 10.19 & -0.30 & 1.55 \\
\hline Social & $8.50(9.89)$ & $7.86(6.47)$ & $4.22(3.34)$ & $6.64(7.27)$ & 9.09 & -0.74 & 1.44 \\
\hline Technical & $1.46(1.38)$ & $1.95(1.79)$ & $1.57(1.59)$ & $2.27(2.29)$ & 0.23 & 0.43 & 0.33 \\
\hline
\end{tabular}

Notes. ${ }^{*} p<.05$; if match condition significantly $>$ a mismatch condition than the match condition is indicated with a

+ and the mismatch condition with a - 
Table 8

Multilevel Analyses for Effects of Match Condition versus Non-matched Conditions concerning Students' Discussion of the Domain

\begin{tabular}{|c|c|c|c|c|c|c|c|}
\hline & $\begin{array}{l}\text { Conceptual } \\
\text { condition } \\
\left(n_{\text {student }}=24\right)\end{array}$ & $\begin{array}{l}\text { Causal } \\
\text { condition } \\
\left(n_{\text {student }}=24\right)\end{array}$ & $\begin{array}{l}\text { Simulation } \\
\text { condition } \\
\left(n_{\text {student }}=24\right)\end{array}$ & $\begin{array}{l}\text { Match } \\
\text { condition } \\
\left(n_{\text {student }}=21\right)\end{array}$ & $\begin{array}{l}\text { Effects } \\
\text { conditi } \\
\text { ( } N_{\text {studen }}\end{array}$ & $\begin{array}{l}\text { natch } \\
\text { n } \\
\text { 93) }\end{array}$ & \\
\hline & $M(S D)$ & $M(S D)$ & $M(S D)$ & $M(S D)$ & $\chi^{2}(3)$ & $\beta$ & $S E$ \\
\hline Concepts & $21.17(15.28)$ & $26.27(20.66)$ & $17.22(13.92)$ & $26.09(14.76)$ & 14.90 & 2.41 & 3.45 \\
\hline Solutions & $20.62(23.12)$ & $29.86(31.24)$ & $21.27(27.24)$ & $16.36(13.26)$ & 14.70 & 1.27 & 3.59 \\
\hline Relations $^{*}$ & $29.17(16.21)$ & $35.73(29.01)$ & $21.30(17.00)-$ & $32.82(15.66)+$ & 17.41 & 1.73 & 4.22 \\
\hline Conceptual & $9.29(4.97)$ & $11.27(9.88)$ & $6.04(4.94)$ & $9.14(5.41)$ & 11.20 & -0.04 & 1.33 \\
\hline Causal & $15.38(10.35)$ & $19.59(17.76)$ & $10.96(1.16)$ & $18.91(10.28)$ & 14.43 & 0.59 & 2.62 \\
\hline Mathematical $^{*}$ & $4.50(5.06)$ & $4.86(3.69)$ & $4.30(5.04)-$ & $4.77(3.53)+$ & 3.90 & 0.17 & 0.84 \\
\hline
\end{tabular}

Notes. ${ }^{*} p<.05$; if match condition significantly $>$ a mismatch condition than the match condition is indicated with a + and the mismatch condition with a -

Table 9 
Multilevel Analyses for Effects of Match Condition versus Non-matched Conditions concerning Students' Communicative Activities

\begin{tabular}{|c|c|c|c|c|c|c|c|}
\hline & $\begin{array}{l}\text { Conceptual } \\
\text { condition } \\
\left(n_{\text {student }}=24\right)\end{array}$ & $\begin{array}{l}\text { Causal } \\
\text { condition } \\
\left(n_{\text {student }}=24\right)\end{array}$ & $\begin{array}{l}\text { Simulation } \\
\text { condition } \\
\left(n_{\text {student }}=24\right)\end{array}$ & $\begin{array}{l}\text { Match } \\
\text { condition } \\
\left(n_{\text {student }}=21\right)\end{array}$ & $\begin{array}{l}\text { Effect } \\
\text { condit } \\
\left(N_{\text {student }}\right.\end{array}$ & $\begin{array}{l}\text { ts match } \\
\text { tion } \\
{ }_{t}=93 \text { ) }\end{array}$ & \\
\hline & $M(S D)$ & $M(S D)$ & $M(S D)$ & $M(S D)$ & $\chi^{2}(3)$ & $\beta$ & $S E$ \\
\hline Coordination $^{*}$ & $124.33(59.01)$ & $173.82(130.42)$ & $87.65(54.21)-$ & $170.36(79.22)+$ & 30.06 & 24.02 & 19.40 \\
\hline Focusing ${ }^{*}$ & $22.87(8.20)-$ & $31.50(23.37)$ & $18.13(12.28)-$ & $31.09(15.83)+$ & 18.42 & 4.30 & 3.52 \\
\hline Checking ${ }^{*}$ & $57.33(31.43)-$ & $88.95(69.43)$ & $39.17(26.471)-$ & $84.14(38.56)+$ & 27.74 & 14.22 & 9.84 \\
\hline Argumentation ${ }^{*}$ & $44.12(26.92)$ & $53.36(43.65)$ & $30.35(19.95)-$ & $55.14(32.18)+$ & 20.90 & 5.41 & 6.61 \\
\hline
\end{tabular}

Notes. ${ }^{*} p<.05$; if match condition significantly $>$ a mismatch condition than the match condition is indicated with a + and the mismatch condition with a - 
Table 10

One-way Multivariate Analysis of Variance for Effects of Match Condition versus

Non-matched Conditions concerning Complex Learning-task Performance

\begin{tabular}{|c|c|c|c|c|}
\hline Criteria & $\begin{array}{l}\text { Conceptual } \\
\text { condition } \\
\left(n_{\text {group }}=8\right)\end{array}$ & $\begin{array}{c}\text { Causal } \\
\text { condition } \\
\left(n_{\text {group }}=8\right)\end{array}$ & $\begin{array}{l}\text { Simulation } \\
\text { condition } \\
\left(n_{\text {group }}=8\right)\end{array}$ & $\begin{array}{c}\text { Match } \\
\text { condition } \\
\left(n_{\text {group }}=7\right)\end{array}$ \\
\hline & $M(S D)$ & $M(S D)$ & $M(S D)$ & $M(S D)$ \\
\hline Suitability & $14.38(2.13)$ & $15.38(0.74)$ & $13.75(1.70)$ & $15.57(2.15)$ \\
\hline Elaboration & $11.62(2.13)$ & $13.50(2.93)$ & $11.75(2.66)$ & $13.71(2.29)$ \\
\hline Justification $^{*}$ & $4.62(2.20)-$ & $7.50(2.67)$ & $4.62(1.51)-$ & $7.57(1.90)+$ \\
\hline Correctness ${ }^{*}$ & $7.12(1.55)-$ & $9.25(2.49)$ & $8.12(1.36)-$ & $9.86(0.69)+$ \\
\hline Continuity & $3.50(0.76)$ & $3.75(0.46)$ & $3.00(0.93)$ & $3.29(0.76)$ \\
\hline Quality advice & $4.00(1.07)$ & $5.00(0.93)$ & $3.88(1.46)$ & $4.43(1.38)$ \\
\hline Total score ${ }^{*}$ & $45.25(7.23)-$ & $54.38(7.98)$ & $45.12(6.53)-$ & $54.43(6.29)+$ \\
\hline
\end{tabular}

Notes. ${ }^{*} p<.05$; if match condition significantly $>$ a mismatch condition than the

match condition is indicated with a + and the mismatch condition with a - 


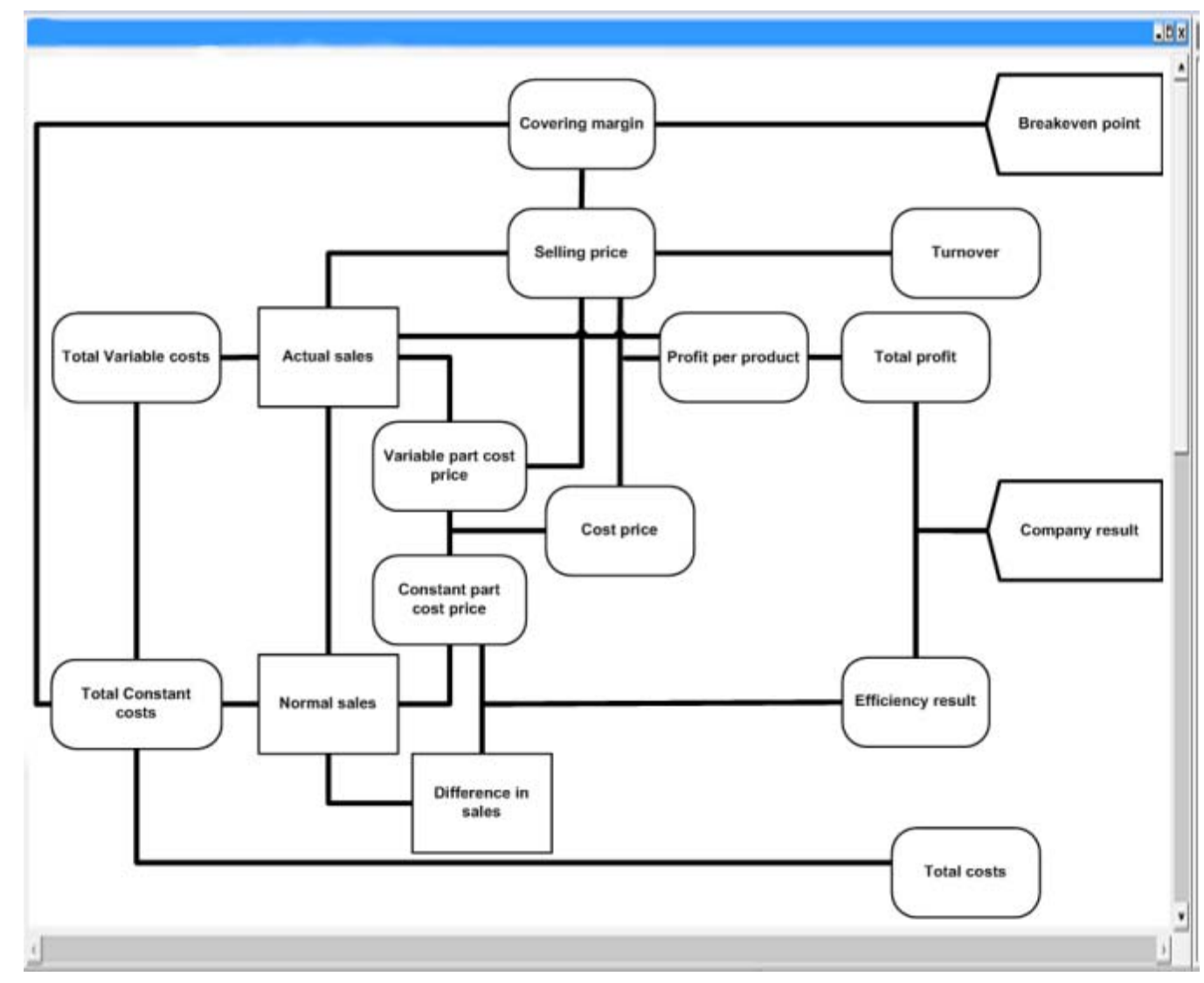

Fig 1. Conceptual representation (expert model) 


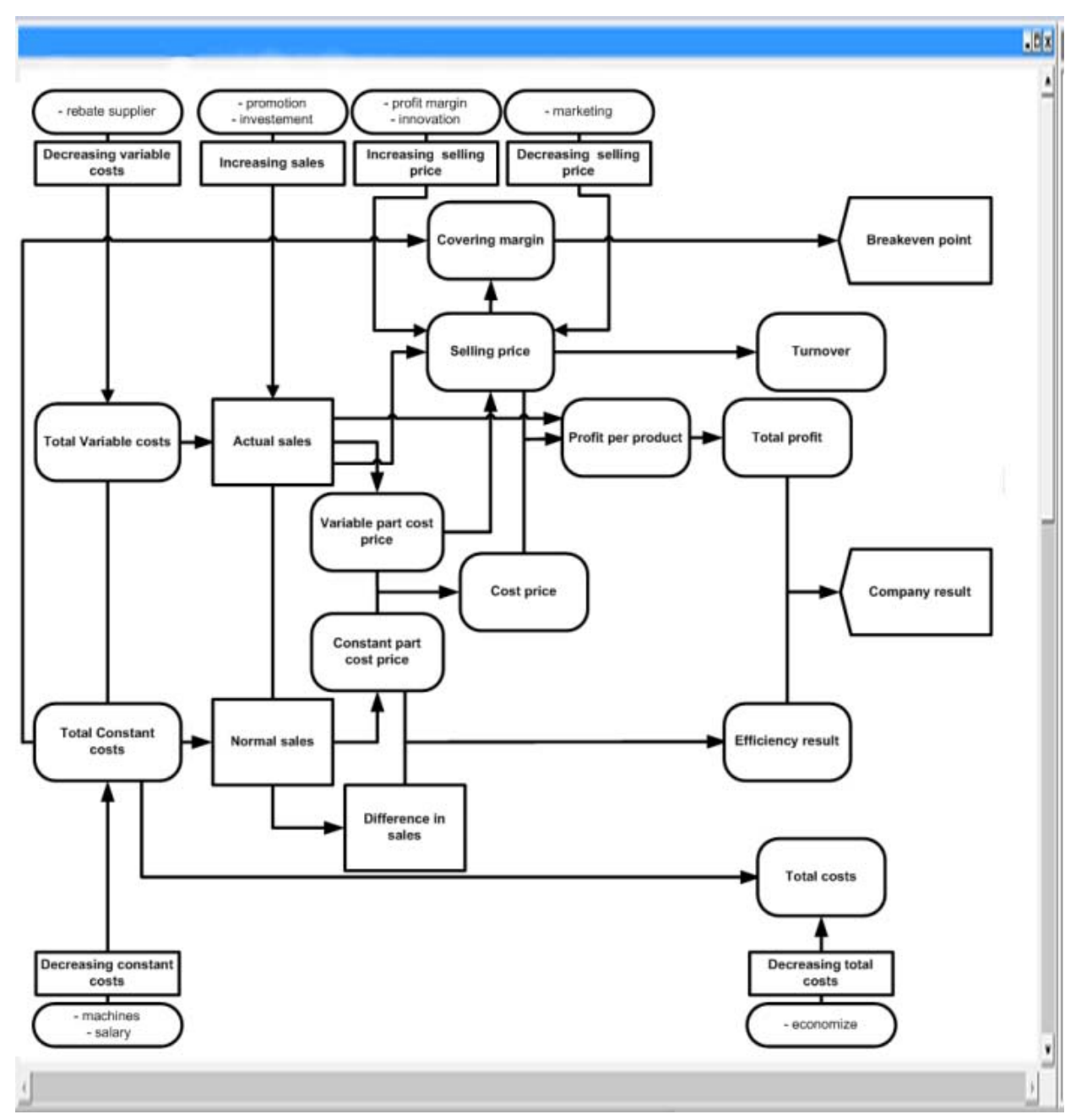

Fig 2. Causal representation (expert model) 


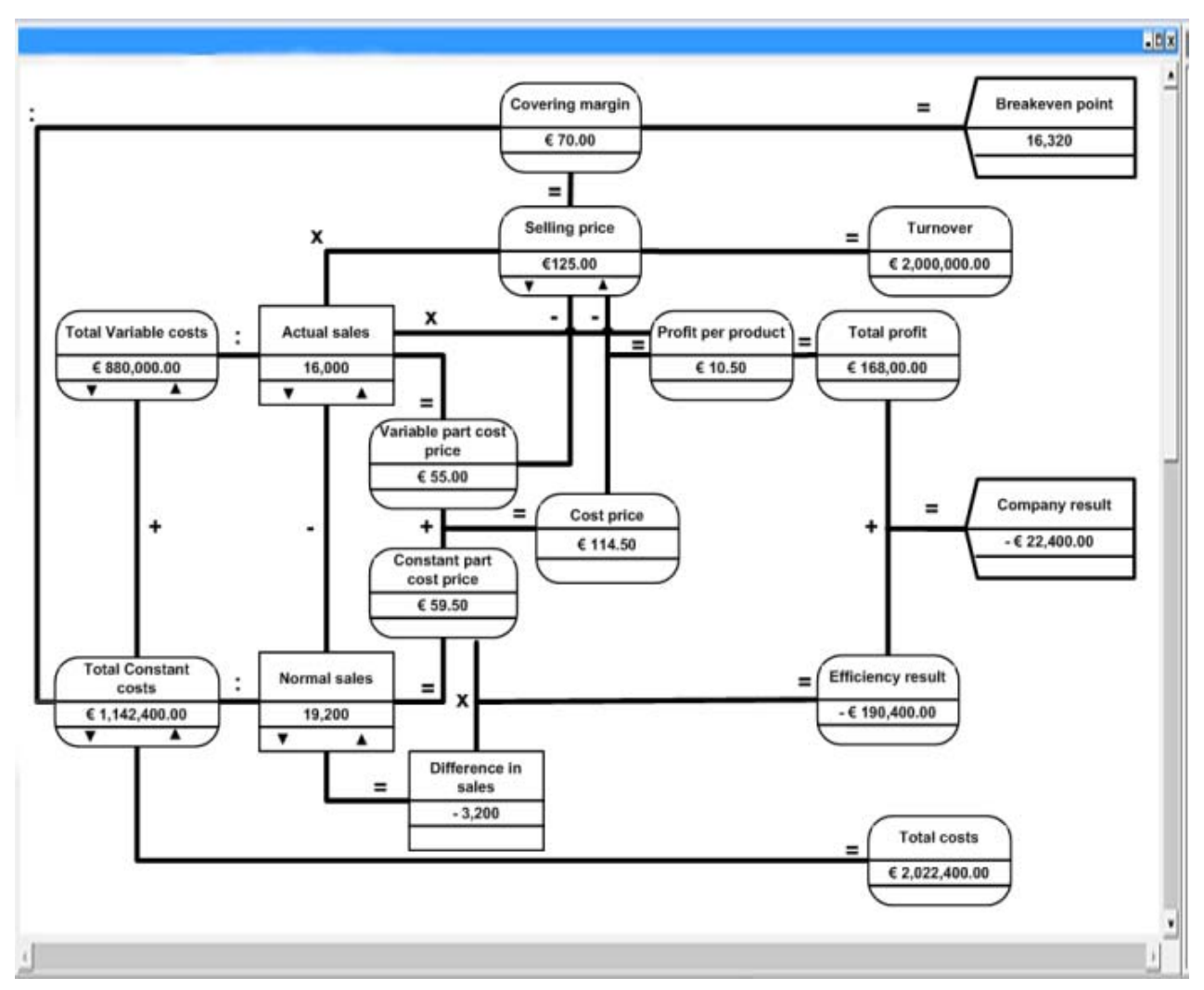

Fig 3. Simulation representation (expert model) 


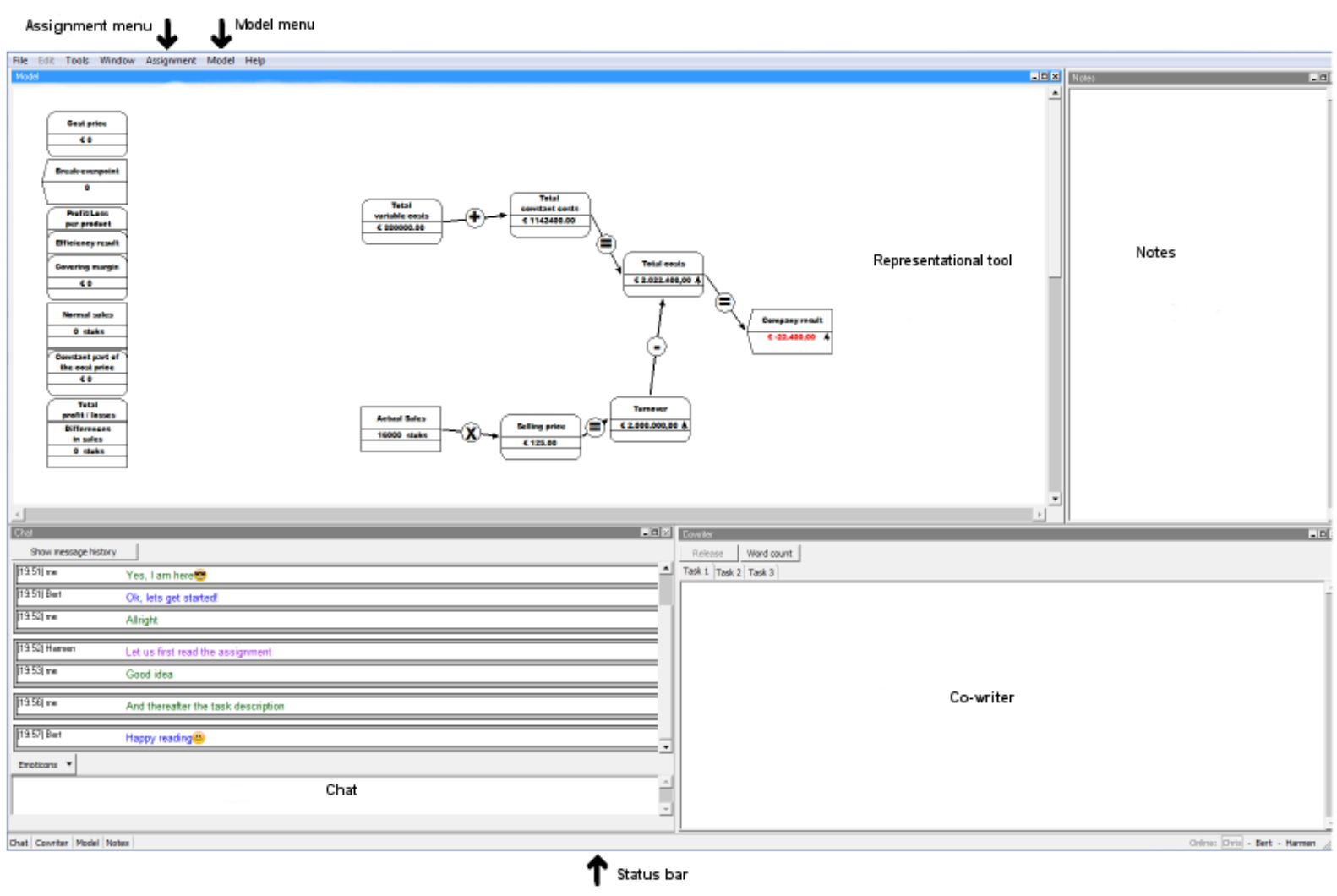

Fig 4. Screenshot of the VCRI-environment (simulation tool) 

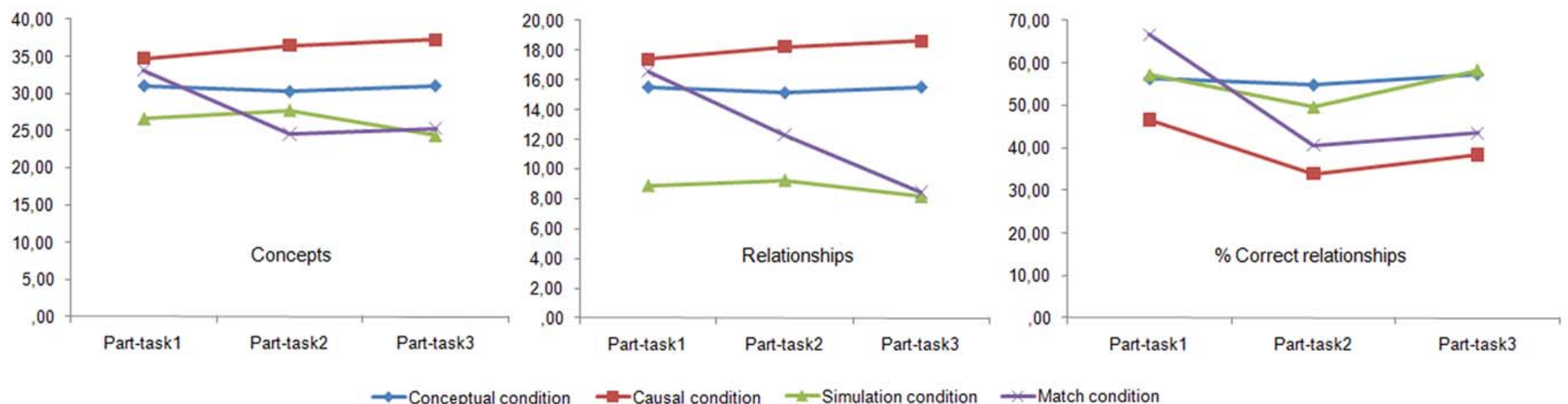

Fig 5. Content analyses for effects of match condition versus non-matched conditions concerning student tool use 